\title{
CLINICAL PROFILE OF NEPHROTIC SYNDROME IN CHILDREN
}

Sahana K.S ${ }^{1}$

\section{HOW TO CITE THIS ARTICLE:}

Sahana K.S. "Clinical Profile of Nephrotic Syndrome in Children". Journal of Evolution of Medical and Dental Sciences 2014; Vol. 3, Issue 04, January 27; Page: 863-870, DOI: 10.14260/JEMDS/2014/1916

ABSTRACT: Background/objective- Nephrotic syndrome is a common renal disease worldwide and an important chronic renal disease in children. This study is undertaken to assess clinical presentation, associated complications, investigative profile and therapeutic response in children with nephrotic syndrome. MATERIALS AND METHODS: Prospective observational study at pediatric department of our tertiary care hospital. 47 children who were diagnosed to have nephrotic syndrome were included in the study. Cases were noted down into the prestructured proforma with respect to history, examination and investigations. Statistical analysis was done by standard descriptive statistics including Chi-square test and calculating the $\mathrm{p}$ value. RESULTS: Children presented between the ages of 2-15 years with mean age at presentation of 7.4 years with male to female ratio of 3.27:1. $36 \%$ of cases presented for the first time and 63\% with relapse. All patients presented with puffiness of face and swelling of limbs and genital edema in $31 \%$. Ascites was present in $63 \%$ of cases, pleural effusion in $15 \%$ of cases and HTN in $12 \%$ of cases. Infections were seen in $31 \%$ of cases with UTI being the commonest infection noted (25\%). On investigation all patients had hypoalbuminemia in the range of 1.3-2.4 gm. / dl and hypercholesterolemia 206-388 $\mathrm{mg} / \mathrm{dl}$. Renal function test was normal in all the patients. Microscopic hematuria noted in $10.6 \%$ of cases. Urine protein was $3+$ in all cases by sulfosalycylic acid method. Urine total protein in a timed 24 hours sample was in the range of $0.8-7 \mathrm{gm} / 24$ hour and mean value was $3.67 \mathrm{gm} / 24$ hours. Protein creatinine ratio in a spot sample of urine was in the range of 3-9.8 and mean value was 4.79. Majority of cases (97\%) were responders to steroid therapy. CONCLUSION: In our study clinical and laboratory data were in concordance with typical nephrotic syndrome in children. Pattern of nephrotic syndrome and response to treatment did not differ significantly from other studies.

KEY WORDS: Nephrotic syndrome, Children, Edema, infections.

INTRODUCTION: Nephrotic syndrome is a common renal disease worldwide and an important chronic renal disease in children. Its incidence is reported to be $2-3 / 100000$ children in western countries, ${ }^{1}$ while as its incidence is slightly higher (2-7/100000) in children with South Asian origin and its prevalence is $12-16 / 100000$ children. $^{2}$

According to Edelmann, ${ }^{1}$ NS is neither a single disease nor even a heterogeneous group of disease. Rather it is a clinical state characterised by heavy proteinuria and hypoalbuminemia, often associated with edema, hypercholesterolemia and hyperlipidemia.

Most children with nephrotic syndrome have a form of primary or idiopathic nephrotic syndrome and the most common glomerular lesion is minimal change disease. The idiopathic nephrotic syndrome most commonly appears between the ages of 2-6 years of age, more common in boys and it is steroid sensitive in majority of cases[95\%]. ${ }^{3}$ The cause of idiopathic nephrotic syndrome is unknown but evidence suggests that primary $\mathrm{T}$ cell disorder leading to glomerular podocyte dysfunction. ${ }^{4}$ The clinical presentation of nephrotic syndrome vary widely from mild edema to severe cases presenting with complications important being life threatening infections and 
thromboembolic episodes. Nephrotic syndrome with significant glomerular lesion can have hypertension, renal insufficiency, and gross haematuria. Overall incidence of MCNS has been generally stable over past 3 decades. However incidence of FSGS seems to be increasing. ${ }^{.}$Secondary nephrotic syndrome due to systemic causes include SLE, HSP, Amyloidosis, DM, HIV, Parvovirus B19, and Hepatitis B AND C virus infections.

There is lack of studies on clinical profile of nephrotic syndrome in Indian children in recent past. Though the incidence of nephrotic syndrome is not changed but due to increased availability of medical services and scattered distribution of patients pediatricians are getting to see less number of cases compared to past. So we decided to do this study in order to assess clinical presentation, associated complications, investigative profile and therapeutic response in children with nephrotic syndrome.

MATERIALS AND METHODS: This study was a prospective observational study conducted at pediatric department. 47 children who were diagnosed to have nephrotic syndrome at a tertiary care hospital in whom steroid therapy was not yet started were included for the study. Both the patients with first attack and relapse were included in the study. Diagnosis of nephrotic syndrome was based on the following criteria - massive proteinuria $>40 \mathrm{mg} / \mathrm{m} 2 / \mathrm{hr}$. or protein creatinine ratio $>2-3: 1$, hypoalbuminemia $<2.5 \mathrm{gm} / \mathrm{dl}$, generalised edema and hypercholesterolemia $>200 \mathrm{mg} / \mathrm{dl}$. Nephrotic syndrome secondary to systemic causes were excluded from the study.

Cases were noted down into the prestructured proforma with respect to history, examination and investigations. Following investigations were done in all suspected cases of nephrotic syndrome. Complete blood count including peripheral smear and ESR, blood urea, serum creatinine serum cholesterol, serum albumin were done in all the patients. Urine was examined for the presence of gross haematuria or cloudy appearance followed by microscopic examination to look for pus cells and RBC, S and urine culture. Urine protein was measured by sulfosalycylic acid test, protein creatinine ratio and 24 hours urine protein measured using Esbach's albuminometer. Chest $\mathrm{x}$ ray and Montoux test were done to rule out tuberculosis. Blood pressure, weight, intake and output chart, abdominal girth, urine for proteinuria were done daily on all patients. Patients were started treatment with steroids according to IAP protocol, ${ }^{[6]}$ along with fluid and salt restriction and their response was noted.

Statistical analysis was done by standard descriptive statistics including chi-square test and calculating the p value. Study was approved by the institutional ethical committee.

RESULTS: In the present study children presented between the ages of 2-15 years with mean age at presentation being 7.4 years. In the present study, 65\% of the cases belonged to 6-12 years age group followed by 1-5 years age group, which accounted for $31 \%$ of the nephrotic syndrome patients. $76 \%$ of the cases were male while as $24 \%$ of cases were female with male to female ratio of 3.27:1 suggesting male preponderance. Table 1 shows age and sex distribution of cases. $36 \%$ of cases presented for the first time (first attack) where as $63 \%$ of patients had one or more relapse at the time of presentation but statistically not significant. (x2-3.596, p<.0.o58). Majority of cases i.e. $76 \%$ of cases presented to the hospital within 10 days of onset of symptoms where as $14 \%$ of cases had duration of symptoms for more than 20 days before coming to hospital. 
ORIGINAL ARTICLE

\begin{tabular}{|c|c|c|c|c|c|c|}
\hline age & Male No. & Male \% & Female No. & Female \% & Total No. & Total \% \\
\hline $0-1$ & - & - & - & - & - & - \\
\hline $1-5$ & 9 & 19 & 6 & 12 & 15 & 31 \\
\hline $6-12$ & 27 & 57 & 4 & 8.5 & 31 & 65.5 \\
\hline$>12$ & - & - & 1 & 2.1 & 1 & 2.1 \\
\hline total & \multicolumn{3}{|c|}{36} & \multicolumn{3}{|c|}{47} \\
\hline
\end{tabular}

All patients presented with puffiness of face and swelling of limbs with diurnal variation noted in $76 \%$ of cases. $76.6 \%$ patients presented with abdominal distension while as $31 \%$ of cases complained of genital swelling. History of decreased frequency and volume of micturition was obtained in $53.9 \%$ while as burning micturition was noted in $4.26 \%$ of cases. Other symptoms include abdominal distension, fever, vomiting and respiratory distress. Figure 1 shows presenting symptoms and their frequency.

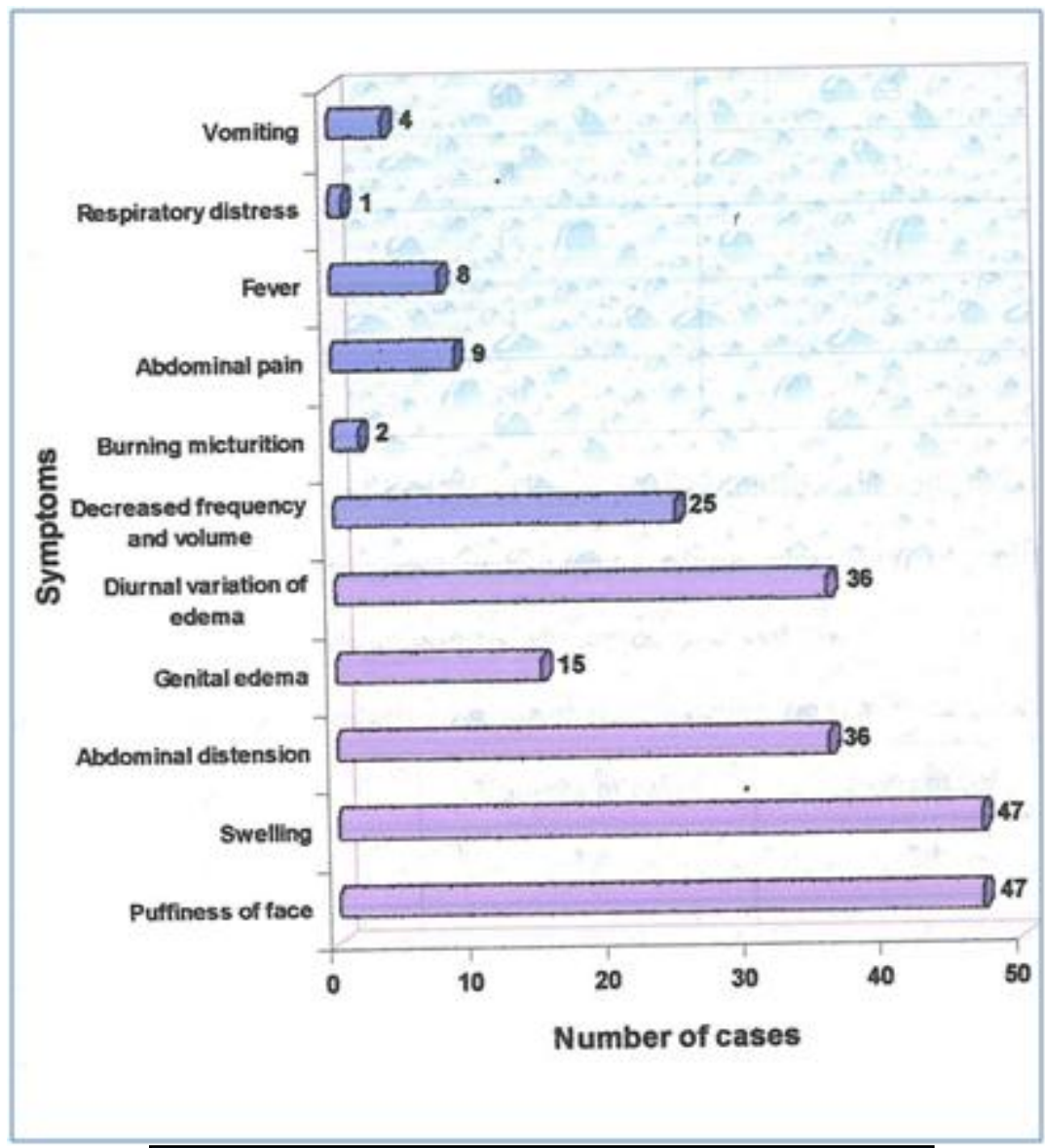

Fig. 1: Graphical representation of presenting symptoms in nephrotic syndrome. 
On examination bilateral pitting pedal edema with facial puffiness was present in $100 \%$ of cases. Ascites was present in $63 \%$ of cases, pleural effusion in $15 \%$ of cases while as hepatomegaly was noted in $8 \%$ of cases. Hypertension was notes in $12 \%$ of cases prior to initiation of corticosteroid therapy. Pallor was noted in $42 \%$ of cases. Figure 2 shows signs on examination and their frequency

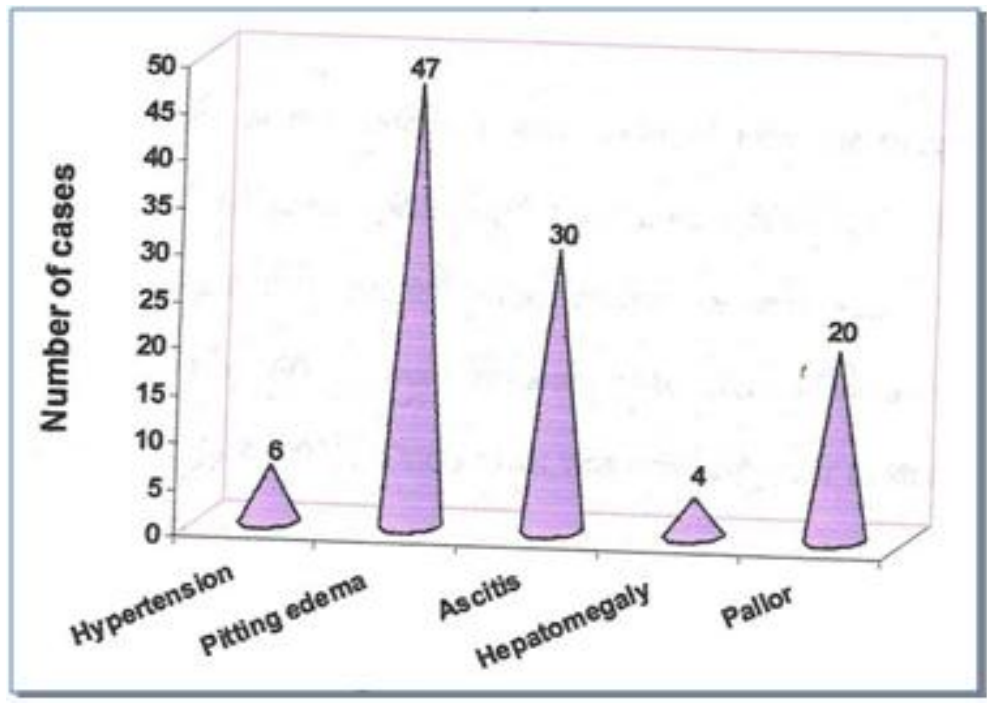

\section{Fig 2: graphical representation of signs in nephrotic syndrome.}

On investigation $74 \%$ of cases had anemia with peripheral smear showing normocytic hypochromic in 26 cases and microcytic hypochromic in 9 cases. Total leukocyte range was between $6200-13,200$ with mean leukocyte count of $7890 / \mathrm{mm}^{3}$. ESR was elevated in all cases with mean ESR of $71 \mathrm{~mm}$ at first hour. On biochemical investigation blood urea was between the range of 14-43 $\mathrm{mg} / \mathrm{dl}$ with mean value of $25 \mathrm{mg} / \mathrm{dl}$. Serum creatinine was in the range of $0.3-1.3 \mathrm{mg} / \mathrm{dl}$ with mean value of $0.63 \mathrm{mg} / \mathrm{dl}$. Serum albumin was between $1.3-2.4 \mathrm{mg} / \mathrm{dl}$ with mean value of $1.9 \mathrm{mg} / \mathrm{dl}$ indicative of hypoalbuminemia. Serum cholesterol range was in between $206-388 \mathrm{mg} / \mathrm{dl}$ with mean level of $294 \mathrm{mg} / \mathrm{dl}$ suggestive of hypercholesterolemia Hypoalbuminemia and hypercholesterolemia was present in all cases. Table 2 shows investigative profile in nephrotic syndrome.

\begin{tabular}{|l|c|c|}
\hline \multicolumn{1}{|c|}{ Parameter } & Range & mean \pm SD \\
\hline Haemoglobin & $8.6-12.4 \mathrm{gm} . / \mathrm{dl}$ & $10.4 \mathrm{gm} / \mathrm{d} \pm 1.32$ \\
\hline Total count l & $6200-13,200$ cells/mm3 & $7890 \pm 1522$ \\
\hline ESR & $15-146 \mathrm{~mm}$ at first hour. & $71 \pm 29$ \\
\hline Blood urea & $14-43 \mathrm{mg} / \mathrm{dl}$ & $25 \pm 7.37$ \\
\hline Serum creatinine & $0.3-1.3 \mathrm{mg} / \mathrm{dl}$ & $0.63 \pm 0.21$ \\
\hline Serum albumin & $1.3-2.4 \mathrm{gm} / \mathrm{dl}$ & $1.9 \pm 0.47$ \\
\hline Serum cholesterol & $206-388 \mathrm{mg} / \mathrm{dl}$ & $294 \pm 61.42$ \\
\hline \multicolumn{2}{|r|}{ Table 2- Investigative profile of Nephrotic syndrome }
\end{tabular}


On urine examination colour of the urine was cloudy in $48 \%$ of cases and there was no case of gross haematuria. Specific gravity of urine was between1020-1060. On urine microscopy Haematuria was noted in 5 cases $(10.6 \%)$ and pyuria noted in 12 cases (25\%). Urine culture was positive in $25 \%$ of cases with E Coli (50\%) being the commonest organism isolated followed by klebsialla (41.6\%) and proteus (8.3\%). Urine protein was $3+$ in all cases by sulfosalycylic acid method. Urine total protein in a timed 24 hours sample was in the range of $0.8-7 \mathrm{gm} / 24$ hour and mean value was $3.67 \mathrm{gm} / 24$ hours. Protein creatinine ratio in a spot sample of urine was in the range of 3-9.8 and mean value was 4.79. Table 3 shows analysis of urinary parameters.

\begin{tabular}{|l|c|}
\hline Cloudy appearance & $23(48 \%)$ \\
\hline Hematuria & $5(10.6 \%)$ \\
\hline Pyuria & $12(25 \%)$ \\
\hline Urine culture positive & $12(25 \%)$ \\
\hline E coli positive & $6(12.5 \%)$ \\
\hline \multicolumn{2}{|l|}{ Table 3 - Analysis of urinary parameters. }
\end{tabular}

Infections were the most common complications [31\%] noted though one patient presented with severe respiratory distress due to massive ascites. UTI was the commonest infection noted (in $25 \%$ of cases $)$ and it is statistically significant $\left(x^{2}=11.255, p<0.001\right)$ followed by pneumonia, tuberculosis and peritonitis (one case each)

Majority of cases (97\%) were responders to steroid therapy and it is statistically significant $(\mathrm{p}<0.001)$. One was non -responder to steroid therapy even after four weeks and labelled him as steroid resistant and patient was referred to Nephrologists. In 5 cases steroids were not started as they underwent spontaneous remission.

DISCUSSION: This study was conducted on 47 children who were diagnosed to have nephrotic syndrome in our institution.

In the present study the age distribution of cases ranged from 2 years to 15 years. The mean age at presentation was 7.4 years. Similar observations were made by Chahar OP et al, ${ }^{7}$ and Shastri NG et al. ${ }^{8}$. Even though commonly nephrotic syndrome is seen in pre-school children in our study the mean age was 7.4 years as majority of cases (63\%) were relapses. Younger the age of onset of nephrotic syndrome more likely is the chance of MCNS ${ }^{9}$. In the present study $(n=47)$ male: female ratio was noted to be 3.27:1 Similar observations were made by Siegal NJ et al. ${ }^{10}$ Among the frequent relapsers, two patients had features of steroid toxicity namely posterior capsular cataract in one case and HTN, osteoporosis in the other case.

In the present study the duration of symptom at the time of presentation ranged from 3 to 45 days. Majority of cases i.e. $76 \%$ presented to the hospital within 10 days of onset of symptoms, whereas $14 \%$ cases had duration of symptoms for more than 20 days prior to hospital. Among the patients who presented late, there were no complications noted except for one case, which had associated tuberculosis. Present study showed face and limbs as the commonest site to be involved i.e. in $100 \%$ similar to observation made by Chowdhary et al. ${ }^{11}$ Edema involving genital area was least it in $31 \%$ of cases where as in a study done by Safaei et al, 12 it was found to be $54.5 \%$. Only one patient presented with respiratory distress due to massive edema (pleural effusion and massive 
ascites). 53\% of cases presented with history of decreased frequency and volume of micturition. Only $4 \%$ cases had burning micturition and all of them had UTI. Other symptoms noted by various studies include anorexia, lethargy, abdominal pain and diarrhoea. ${ }^{11,12}$

In the present study, HTN was noted in 6 cases $(12 \%)$ prior to initiation of steroid therapy. As there were no other associated features like haematuria or renal insufficiency to suggest significant glomerular lesion, these children were not investigated further and they responded to steroid therapy. In a review of ISKDS study by Struss.J et al, ${ }^{13}$ hypertension was found to be present in $20.7 \%$ of cases with MCNS and in $25.7 \%$ of cases with other histological types. According to Nelson, hypertension can be present in about $10 \%$ of MCNS while as nephrotic syndrome due to significant glomerular lesion, the incidence of HTN varies from $20-35 \%$.

On examination pitting type of edema was noticed in all patients in the present study. Generalised edema with ascites was present in $63 \%$ of cases which is similar to study done Safaei et al. ${ }^{12}$ Other uncommon sign noted was hepatomegaly present in $8.5 \%$ of cases.

Present study ( $\mathrm{N}=47)$ showed UTI, peritonitis, tuberculosis, pneumonia to be present in $25 \%, 2 \%, 2 \%$ and $2 \%$ of cases respectively. In contrast to our study UTI was present only in $8.1 \%$ of cases in a study done by Ajayan et al [14]14 but observed a higher incidence of pneumonia (35\%). Gorensek Mj et al, ${ }^{15}$. ( $\mathrm{N}=214$ ) in a 20 year retrospective study observed $17.3 \%$ cases of peritonitis. Smaller percentage observed in our study could be attributed to small number of sample size and short duration of study whereas Gorensek et al, ${ }^{15}$ studied for a period of 20 years.

In the present study $74 \%$ of cases had anaemia and both normocytic and microcytic pictures were seen. Iron deficiency anaemia in nephrotic syndrome is attributed to loss of transferrin in the urine. In a study done by Anochie et al nearly half of the patients had anaemia. ${ }^{16}$

Renal function was normal in all the patients. Serum albumin ranged from $1.3 \mathrm{gm}$ to $2.4 \mathrm{gm} / \mathrm{dl}$ with the mean level of $1.9 \mathrm{gm} / \mathrm{dl}$. Similar observations made Hiaoka et al. ${ }^{17}$ The range of serum cholesterol in the present study was $206-308 \mathrm{mg} / \mathrm{dl}$ and the mean serum cholesterol was noted to be $294 \mathrm{mg} / \mathrm{dl}$. Similar observations were made by Appeal GB et al, 18

On microscopic examination in the present study $10.6 \%$ of cases showed presence of haematuria. Similar observations were made by Siegal NJ et al. ${ }^{10}$. Among 5 of these cases with microscopic haematuria, three cases had UTI while rest of the two cases responded to steroids and haematuria subsided. Siegal NJ et al have discussed the cause of haematuria and observed that microscopic haematuria may be either asymptomatic or accompany UTI whereas macroscopic haematuria in patients of nephrotic syndrome should be expected only in cases with UTI, renal vein thrombosis and other secondary causes of nephrotic syndrome associated with significant glomerular lesions. In a study done by Ali AM et al 10 patients (out of 231) had gross haematuria and on biopsy FGCS was found in 6 and mesangial proliferative and membranoproliferative in 2 each. ${ }^{19}$

In the present study urine total protein in timed 24 hour sample the range observed was 0.8 $7 \mathrm{gms} / 24$ hour with mean value of $3.67 \pm 1.4 \mathrm{gm}$. / 24 hour. Iyer Rs et al, ${ }^{20}$ found the range of timed 24 hours urine protein to be 1.6-8.6gm/24 hour and a mean value of 4.6/24 hour was observed In the present study $(n=47)$ the range of urine protein/ creatinine value observed was 3-9.8 with a mean of UP/UC 4.79. In the various studies, 7, 8, 20, 21 done previously range of UP/UC ratio in nephrotic syndrome was 1.2-9.8 but the mean value is more than 2 in all the studies.

In the present study $2.4 \%$ cases ( 1 case) was non-responder to steroid therapy while as in a study by KIM JS et al, 22 it was found to be about $15 \%$ may be because they have included patients 
upto 18 years of age. They have also found that steroid resistance is more in American and African children. As we have noted that $97.6 \%$ of cases were responders to steroid therapy similar observations were made by Madani et al, 15 and they have also noted that $96 \%$ of children with MCNS were responders to steroid therapy though in our study histopathological picture was not available. Steroid responsiveness is of greater prognostic use than renal histology. ${ }^{4}$

There was no mortality in our case series

CONCLUSION: In our study clinical and laboratory data were in concordance with typical nephrotic syndrome in children. Pattern of nephrotic syndrome and response to treatment did not differ significantly from other studies.

\section{REFERENCES:}

1. Nash MA, Edelmann CM, Bernstein J, Barnett HL. The nephrotic syndrome. Volume 11.Pediatric Kidney Disease, 2nd edition. Boston: Little Brown and Company1992;1247-66

2. Bagga A, Mantan M. Nephrotic syndrome in children. Indian J Med Res 2005, 13-28

3. Pais P, Eliis DA. Nephrotic syndrome, in Nelson Textbook of Pediatrics, 19th edition, ed, Kleigman RM, Stanton BF, Geme JW, Schor NF, Behrman RE, Saunders Elsevier, New Delhi 2012, p 1801-06

4. Eddy AA, Symons JM. Nephrotic Syndrome. Lancet 2003, 362(9384), 629-39

5. Madani A, Fahimi D, Taghaodi R, Mahjoob F, Hajizadeh N, Navabi B. An estimation of steroid responsiveness of idiopathic nephrotic syndrome in Iranian Children. Iran J Pediatric 2010.20(2); 199-205

6. Indian Pediatric nephrology group and Indian academy of paediatrics. Management of steroid sensitive nephrotic syndrome. Revised guidelines. Indian Pediatr 2008;45:203-214

7. Chahar OP, Bundella B, Chahar CK, Purohit M. Quantitation of proteinuria by use of single random spot urine collection. J Indian Med Assoc 1993; 991:86-87.

8. Shastri NJ, Shendurnikar N, Nayak U, Kotwcha PV. Quantitation of proteinuria by protein creatinine ratio. Indian Pediatrics 1994;31;334-37

9. Alhassan A, Mohammed W, Alhymed M. Pattern of childhood nephrotic syndrome in Alijoog region, Saudi Arabia. Saudi journal of kidney diseases. and Transplantation 2013;24(5);105054

10. Siegal NJ, Golberg B, Krassner CS. Long term follow up of children with steroid responsive nephrotic syndrome. J Pediatr 1972;81;251-58

11. Chowdhary EUA, Huq MN, Jaigirdhar MA. Pattern of nephrotic syndrome in children admitted in Bangladesh medical college hospital. Bangladesh medical college journal 2010;15(2);67-73

12. Safaei AASL, Maleknejad S. Clinical and laboratory finding and therapeutic responses in children with nephrotic syndrome. Indian J nephrol 2011;21(1);9

13. Strauss j, Zillreeulo G, Freundlich M. Less commonly recognized features of childhood nephrotic syndrome. Pediatr Clin North Am.1987; 34:591-607.

14. Ajayan P, Krishnamurthy S, Biswal N, Mandel J. clinical spectrum and predictive risk factors of major infections in hospitalized children with nephrotic syndrome. Indian pediatr 2013;50(8):779-81 


\section{ORIGINAL ARTICLE}

15. Gorenek MJ, Lebel MH, Nelson JD. Peritonitis in children with nephrotic syndrome. Pediatrics.1988;81;849-56

16. Anochie I, Eka F, Okpere A. Childhood nephrotic syndrome: change in pattern and response to steroids. J Nati med Assoc, 2006;98(12);1977-81

17. Hiraoka M, Takeda N, Tsukahara H, Kimura K, Takagi K, Havashi S et al. Favorable course of steroid responsive nephrotic children with mild initial attack. Kidney Int1995;47(5):1392-3

18. Appel GB, Blum CB, Chien S. The hyperlipedemia of the nephrotic syndrome-relation to plasma albumin concentration, oncotic pressure, viscosity. N Eng J Med 1985;312:1544-48

19. Ali A, Alii D, Mehran H, Ali Z. Idiopathic nephrotic syndrome in Iranian children. Indian pediatr 2008;45:52-53

20. Iyer RS, Shailaja SN, Bhaskaranand N, Baliga M, Venkatesh A. Quantitation of proteinuria using protein creatinine ratio in random urine samples. Indian Pediatr 1991;28:463-67

21. Abitbol C, Zilleruelo G, Freundlich M, Strauss M. Quantification of proteinuria with urinary protein creatinine ratios and random testing with dipsticks in nephrotic children. J Pediatr 1990;116(2);243-47

22. Kim JS, Bellew CA, Silverstein DM, Aviler DH, Boineau FG, Vehaskari VM. High incidence of initial and late steroid resistance in childhood nephrotic syndrome. Kidney Int2005; 68(3); 1275-81.

\section{AUTHORS:}

1. Sahana K.S.

\section{PARTICULARS OF CONTRIBUTORS:}

1. Assistant Professor, Department of Paediatrics, Sapthagiri Institute of Medical Sciences and Research Centre, Bangalore.

\section{NAME ADDRESS EMAIL ID OF THE} CORRESPONDING AUTHOR:

Dr. Sahana K.S., C/o. Sathish Rao, \#12, Nesara, 2A Cross, Basavasamithi Layout, Vidyaranyapura, Bangalore - 97.

E-mail: dr_sahana2003@yahoo.co.in

Date of Submission: 27/12/2013. Date of Peer Review: 28/12/2013. Date of Acceptance: 10/01/2014. Date of Publishing: 21/01/2014. 